Gut, 1967, 8, 29

\title{
Inhibitory action of cholecystokinin on acid secretion from Heidenhain pouches induced by endogenous gastrin
}

\author{
JOHN C. BROWN AND D. F. MAGEE \\ From the Department of Physiology, University of British Columbia, Vancouver, Canada, \\ and the Department of Pharmacology, University of Washington School of Medicine, \\ Seattle, U.S.A.
}

EDITORIAL COMMENT Cholecystokinin will inhibit acid output during the hormonal phase of gastric secretion.

Kosaka and Lim (1930) demonstrated that extracts from the upper intestine would inhibit gastric secretion from dogs with Heidenhain pouches. The degree of inhibition produced was similar to that observed after the oral ingestion of fat. Similar doses of the extract were shown to have no effect on either pancreatic or biliary secretion. Gillespie and Grossman (1964) have demonstrated that cholecystokinin will inhibit acid secretion in Heidenhain pouches which has been induced by exogenous gastrin and histamine. The inhibitory effect was greater on exogenous gastrin-induced acid secretion than on histamine-induced acid secretion.

The study reported here was undertaken to observe the effect of the Vitrum preparation of cholecystokinin-pancreozymin on acid secretion stimulated by release of endogenous gastrin. Endogenous gastrin was released from denervated antral pouches by perfusing with acetylcholine and peptone solutions. The acid secretion from Heidenhain pouches induced by the release of endogenous gastrin and the effect of cholecystokinin-pancreozymin extract on this acid secretion was observed.

MATERIALS AND METHOD

Five dogs ranging in weight from 14 to $20 \mathrm{~kg}$. were prepared with Heidenhain fundic pouches and denervated antral pouches. The animals were fasted for 24 hours before each test. The action of cholecystokinin from Vitrum (Sweden) was observed on a plateau of acid secretion stimulated by the release of endogenous gastrin.

'Present address: Department of Physiology, The Creighton University, Omaha, Nebraska.
Gastrin was released by perfusing the denervated antrum with a solution of $5 \%$ peptone $p \mathrm{H} 6.5$ (Merck) or a solution of acetylcholine chloride $(0.1 \%$ in $0.9 \%$ saline $)$ $p \mathrm{H}$ 5.5-6.0. The Heidenhain pouch was perfused with $25 \mathrm{ml}$. of $0.9 \%$ saline at body temperature and the pouch washed through with a further $25 \mathrm{ml}$. of saline at the end of each 15-minute collection period. The perfusate and the washout were combined and a $20 \mathrm{ml}$. aliquot was used for $\mathrm{H}^{+}$determination.

Output of $\mathrm{H}^{+}$was determined by titrating a $20 \mathrm{ml}$. sample of the Heidenhain pouch washout against 0.025 $\mathrm{N}$ sodium hydroxide to $p \mathrm{H} 7.0$ using a $p \mathrm{H}$ meter (Radiometer type TTT 1). Acid output was determined in milliequivalents of $\mathrm{H}^{+}$

When the acid secretion from the Heidenhain pouch had reached a plateau, i.e., the $\mathrm{H}^{+}$output in three consecutive periods being approximately constant, cholecystokinin was infused intravenously, over a period of 10 minutes, the dose being $1 \cdot 0-2 \cdot 0$ units $/ \mathrm{kg}$. body weight.

The percentage inhibition produced by cholecystokinin was obtained by comparing the mean acid output from the three periods before the cholecystokinin infusion with the period in which maximum inhibition was observed. This was usually the first or second period following the cholecystokinin infusion.

\section{RESULTS}

Table I shows the effect of intravenous infusion of 2.0 units $/ \mathrm{kg}$. body weight of cholecystokinin on the response of the Heidenhain pouches to perfusing the antrum with $5 \%$ peptone solution in water. A plateau of acid secretion was usually achieved after one-and-a-half to two hours. This plateau was maintained for three 15-minute periods before cholecystokinin infusion was started. Acid secretion was 
TABLE I

EFFECT OF INFUSION OF CHOLECYSTOKININ $(1 \cdot 0-2 \cdot 0$ UNIT/KG BODY WEIGHT) ON ACID RESPONSE OF HEIDENHAIN POUCH TO PERFUSING ANTRUM WITH $5 \%$ PEPTONE.

\begin{tabular}{|c|c|c|c|}
\hline \multirow[b]{2}{*}{ Dog No. } & \multicolumn{3}{|l|}{ Control $^{1}$} \\
\hline & $\begin{array}{l}H^{+} \text {Output } \\
\text { (mEq./15 min.) }\end{array}$ & $\begin{array}{l}H^{+} \text {Output after } \\
\text { Cholecystokinin }^{2}\end{array}$ & $\begin{array}{l}\text { Inhibition (\%) } \\
\text { of } \mathrm{H}^{+} \text {Output }\end{array}$ \\
\hline \multirow[t]{2}{*}{1} & 0.173 & 0.019 & 89 \\
\hline & 0.315 & $0 \cdot 135$ & 57 \\
\hline \multirow[t]{2}{*}{2} & $0 \cdot 176$ & 0.076 & 57 \\
\hline & 0.375 & $0 \cdot 135$ & 64 \\
\hline \multirow[t]{2}{*}{3} & 0.563 & 0.213 & 62 \\
\hline & 0.612 & 0.201 & 67 \\
\hline \multirow[t]{2}{*}{4} & 1.411 & 0.275 & 81 \\
\hline & 1.508 & 0.261 & 83 \\
\hline \multirow[t]{2}{*}{5} & 0.520 & 0.101 & 81 \\
\hline & 0.581 & 0.083 & 85 \\
\hline
\end{tabular}

${ }^{1}$ Control is the mean of three 15 -minute periods before cholecystokinin infusion.

${ }^{2}$ Period of maximum inhibition.

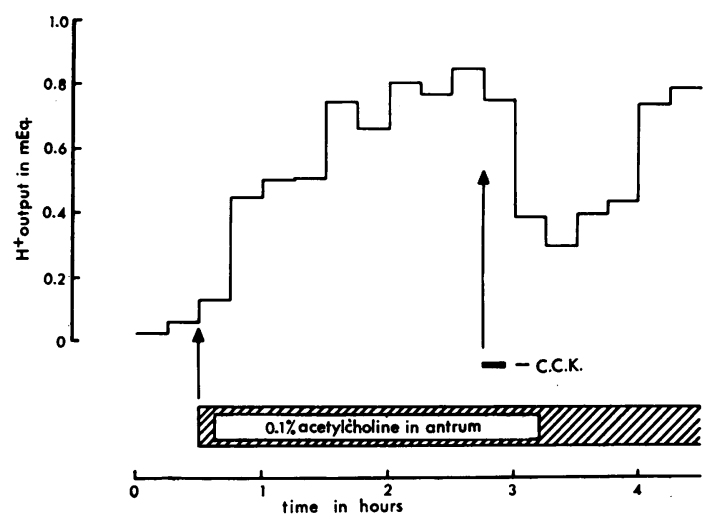

FIG. 1. Acid output from the Heidenhain pouch was stimulated by perfusing the denervated antrum with $5 \%$ peptone solution in water. CCK represents a 10-minute intravenous infusion of 1.0 unit $/ \mathrm{kg}$. cholecystokinin. There is marked depression of acid secretion, lasting for 30 minutes, then a return to control levels.

significantly depressed by the cholecystokinin. This depression was observed in the second or third 15minute period following the infusion. The mean percentage inhibition was $72.6 \pm 3.9 \%$ (mean \pm S.E.).

A typical experiment is illustrated by Figure 1.

Table II shows the effect of intravenous infusion of 1.0 units $/ \mathrm{kg}$. body weight of cholecystokinin on the response of the Heidenhain pouches to perfusing the antrum with $0.1 \%$ acetylcholine chloride solution in $0.9 \%$ saline. Inhibition occurred in the second or third 15-minute period similar to when peptone was used in the antrum. The mean percentage inhibition was $76 \cdot 0 \pm \mathbf{4 \cdot 3} \%$ (mean \pm S.E. $)$.
TABLE II

EFFECT OF INFUSION OF CHOLECYSTOKININ (1·0-2.0 UNIT/KG. BODY WEIGHT) ON ACID RESPONSE OF HEIDENHAIN POUCH TO PERFUSING ANTRUM WITH $0.1 \%$ ACETYLCHOLINE

\begin{tabular}{cccc} 
Dog No. & $\begin{array}{l}\text { Control }^{1} \\
\begin{array}{l}H^{+} \text {Output } \\
(\text { mEq./15 min. })\end{array}\end{array}$ & $\begin{array}{c}H^{+} \text {Output after } \\
\text { Cholecystokinin }^{2}\end{array}$ & $\begin{array}{c}\text { Inhibition (\%) } \\
\text { of } H^{+} \text {Output }\end{array}$ \\
\hline 1 & 0.832 & 0.296 & 64 \\
2 & 0.532 & 0.250 & 53 \\
& 0.418 & 0.052 & 85 \\
3 & 0.339 & 0.060 & 82 \\
& 0.619 & 0.200 & 67 \\
4 & 0.658 & 0.210 & 68 \\
5 & 2.124 & 0.636 & 70 \\
& 2.884 & 0.287 & 90 \\
& 0.570 & 0.091 & 84 \\
& 0.541 & 0.015 & 97
\end{tabular}

${ }^{1}$ Control is the mean of three 15 -minute periods before cholecystokinin infusion.

${ }^{2}$ Period of maximum inhibition.

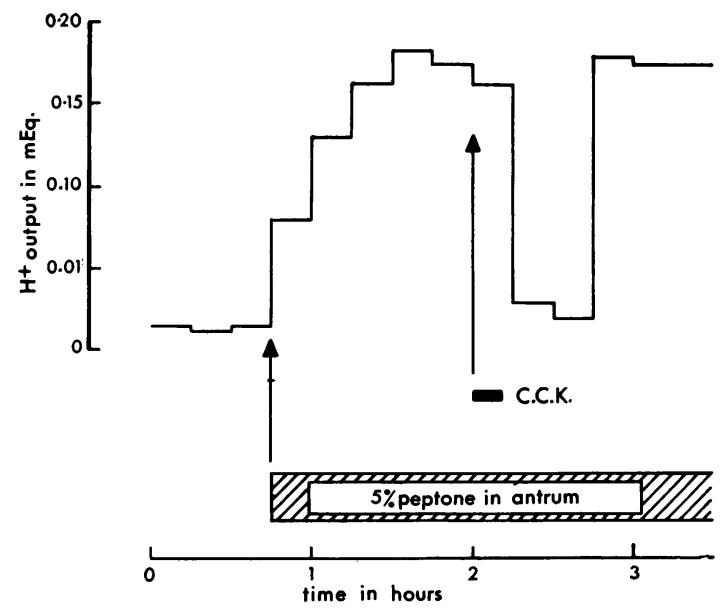

FIG. 2. Acid output from the Heidenhain pouch was stimulated by perfusing the denervated antrum with $0.1 \%$ acetylcholine in $0.9 \%$ saline. CCK represents a 10 -minute intravenous infusion of 1.0 unit/kg. cholecystokinin. There is a marked depression of acid secretion, lasting for over 60 minutes, then a return to control levels.

Figure 2 illustrates inhibition produced as described in the methods.

\section{DISCUSSION}

In 1930, Kosaka and Lim reported that an extract of the upper small intestine will inhibit acid secretion from Heidenhain pouch dogs. Greenlee, Longhi, Guerrero, Nelsen, El-Bedri, and Dragstedt (1957) reported that intravenous injections of secretin (Eli Lilly \& Co.) produced a marked inhibition of gastric secretion as well as a profound stimulation of pancreatic juice. Inhibition of acid secretion was produced when the stimulus for secretion was 
endogenous gastrin released by perfusion of the isolated antrum with $3 \%$ liver solution or a test meal. Inhibition was not produced when the stimulus for acid secretion was histamine and insulin hypoglycaemia. They concluded that the secretin extract produced inhibition only to the hormonal phase of gastric secretion, and that secretin was probably inhibiting the release of gastrin. Gillespie and Grossman (1964) demonstrated that secretin and cholecystokinin extracts (Vitrum, Sweden) would produce inhibition of secretion from Heidenhain pouches induced by exogenous gastrin, cholecystokinin being more potent in its inhibitory effect than secretin.

In our experiments we have shown that cholecystokinin will produce a profound inhibition of gastric secretion induced by endogenous gastrin. There was no significant difference in the degree of inhibition produced, whether gastrin was released by perfusing the antrum with acetylcholine or peptone solutions. It would appear that cholecystokinin will inhibit acid output produced during the hormonal phase of gastric secretion.

This work was supported by grants from the Medical Research Council of Canada (MA-1972) and the United States Public Health Service (AM-02472 and AM-05277).

\section{REFERENCES}

Kosaka, T., and Lim, R. K. S. (1930). Demonstration of the humoral agent in fat inhibition of gastric secretion. Proc. Soc. exp. Biol. (N.Y.), 27, 890-891.

Gillespie, I. E., and Grossman, M. I. (1964). Inhibitory effect of secretin and cholecystokinin on Heidenhain pouch responses to gastrin extract and histamine. Gut, 5, 342-345.

Greenlee, H. B., Longhi, E. H., Guerrero, J. D., Nelsen, T. S., ElBedri, A. L., and Dragstedt, L. R. (1957). Inhibitory effect of pancreatic secretin on gastric secretion. Amer. J. Physiol., 190, 396-402. 